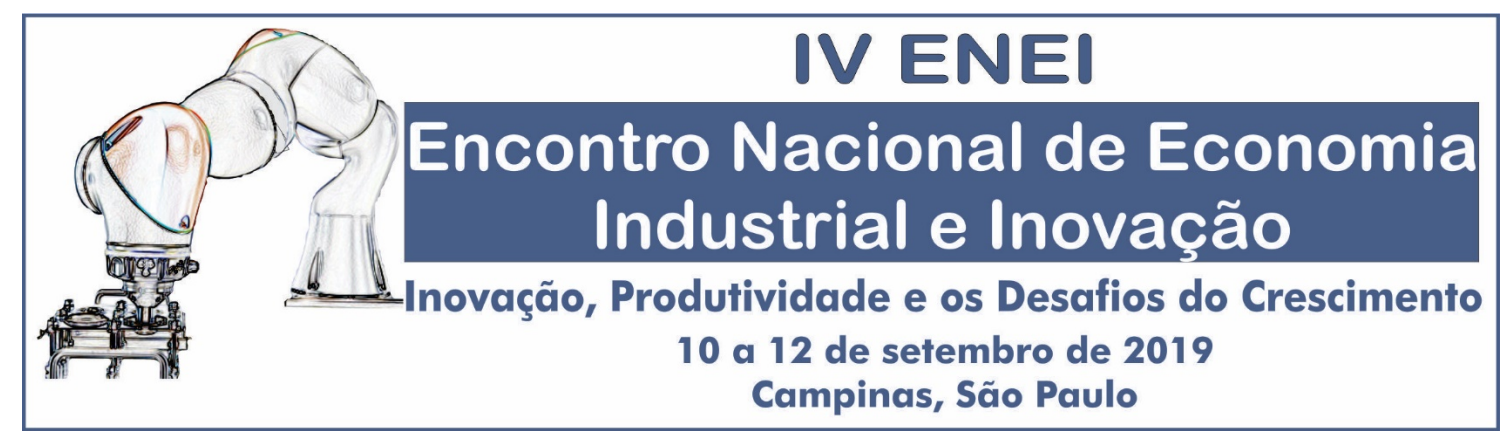

\author{
THAIS MARIA MOZER ${ }^{1}$
}

VANESSA DE LIMA AVANCI ${ }^{2}$

NATHAN MARQUES DIIRR ${ }^{3}$

\title{
PRODUTIVIDADE DA INDÚSTRIA DE TRANSFORMAÇÃO NO ESPÍRITO SANTO: UMA ANÁLISE PARA O PERÍODO DE 2007 A 2016.
}

\footnotetext{
${ }^{1}$ Mestre em economia pela Universidade Federal do Espírito Santo (UFES). Analista de Estudo e Pesquisa SR do Instituto de Desenvolvimento Educacional e Industrial do Espírito Santo (IDEIES).

${ }^{2}$ Doutora em Economia pela Universidade Federal Fluminense (UFF). Analista de Estudo e Pesquisa SR do Instituto de Desenvolvimento Educacional e Industrial do Espírito Santo (IDEIES).

${ }^{3}$ Graduado em Ciências Econômicas pela Universidade Federal do Espírito Santo (UFES). Analista de Estudo e Pesquisa PL do Instituto de Desenvolvimento Educacional e Industrial do Espírito Santo (IDEIES).
} 


\section{PRODUTIVIDADE DA INDÚSTRIA DE TRANSFORMAÇ̃̃O NO ESPÍRITO SANTO: UMA ANÁLISE PARA O PERÍODO DE 2007 A 2016.}

Resumo: O presente artigo aborda a evolução da produtividade do trabalho na indústria do estado do Espírito Santo no período de 2007 a 2016. Esta medida também foi comparada relativamente à produtividade das mesmas atividades industriais no país e decomposta setorialmente a partir da técnica do shift-share. O estudo apontou para uma retração da produtividade da indústria geral no estado, resultante da combinação de redução no valor da transformação industrial e aumento da população ocupada durante os anos estudados. Ainda assim, a indústria geral no Espírito Santo apresentou uma produtividade relativamente superior a nacional para todos os anos analisados. Porém, quando analisada apenas as indústrias de transformação, a produtividade relativa no Espírito Santo foi inferior a nacional. Portanto, podese inferir que a produtividade da indústria geral no estado somente foi superior à média para o país no período analisado devido ao desempenho das suas indústrias extrativas. A decomposição shift-share da produtividade no estado capixaba entre 2007 e 2016 mostrou que a queda na indústria de transformação não foi um fenômeno generalizado entre os seus setores e que alguns se destacaram, como a produção de alimentos.

Palavras-chave: produtividade; shift-share; indústria de transformação.

Abstract: This paper addresses the evolution of labor productivity in the state of Espírito Santo from 2007 to 2016. This measure was also compared for the performance of industrial activities in the country and decomposed sectorally from the shift-share technique. The study shows a retraction of industrial productivity by a reduction of the industrial production value and an increase of population during the years studied. Nevertheless, when compared to the national average, productivity in the general industry in Espírito Santo showed a higher value for all the years analyzed. However, the results for the manufacturing industry only were lower in Espírito Santo than the national average in the same period. Therefore, it can be inferred that the productivity of the general industry in the state was only higher than the average for the country in the analyzed period due to the performance of its extractive industries. The shift-share decomposition of productivity in the state of Espírito Santo between 2007 and 2016 showed that the decline in the manufacturing industry was not a generalized phenomenon among its sectors and that some stood out, such as food production.

Keywords: productivity; shift-share; manufacturing industry.

\section{Introdução}

A produtividade é considerada um dos motores fundamentais para o crescimento econômico no longo prazo, ao ponto de se considerar que a capacidade de um país de melhorar seu padrão de vida ao longo do tempo depende, quase que inteiramente, de sua capacidade de aumentar a produção por trabalhador (Krugman, 1997). De modo geral, o crescimento da produtividade depende dos ganhos de eficiência na utilização dos insumos produtivos (trabalho e capital) e, em particular, do ritmo de adoção e de difusão das inovações tecnológicas. Além disso, o deslocamento de trabalhadores de atividades econômicas menos produtivas para aquelas que são mais produtivas também é um fator muito importante para o crescimento. 
Entre as atividades econômicas, a indústria de transformação é apontada, pela literatura econômica, como a de maior propensão a disseminar os ganhos de produtividade para toda a economia devido às suas amplas cadeias produtivas e à capacidade de encadeamento das mesmas (Kaldor, 1957; Dosi, Pavitt e Soete, 1990). O conceito de encadeamentos para frente e para trás diz que as atividades da indústria formam elos produtivos com outras atividades econômicas que lhe fornecem insumos e/ou que consomem os bens industriais. Essa articulação gera um efeito cumulativo de desenvolvimento, tal que o incremento de produtividade em um setor tem efeitos multiplicadores sobre a renda dos demais (Hirschman, 1958). Disso resulta que seus ganhos de produtividade são fundamentais para a evolução produtiva de toda a economia. Além disso, a indústria transmite os ganhos de produtividade através da difusão do progresso técnico e da modernização, ao criar novas tecnologias que aumentam a produtividade em outras atividades econômicas (Rodrik, 2008).

O tema da produtividade é central à discussão recente em torno da desaceleração do crescimento econômico brasileiro. Segundo De Negri e Cavalcante (2014), o ciclo de crescimento da economia brasileira ao longo da primeira década dos anos 2000 foi essencialmente impulsionado por fatores demográficos e do mercado de trabalho. No entanto, esses fatores não foram suficientes para manter o ritmo de crescimento após a crise de 2008, tanto pela proximidade do pleno emprego quanto pelo fato do estoque de capital não ter crescido de forma compatível com o crescimento da economia, dada a resiliência da taxa de investimento (De Negri e Cavalcante, 2014). Portanto, o aumento da produtividade é visto como um fator crítico para impulsionar um novo ciclo crescimento econômico no Brasil.

Em outros estudos recentes constatou-se que, desde o início dos anos 2000, a produtividade da indústria de transformação brasileira estava em queda (Canêdo Pinheiro e Barbosa Filho, 2011, Bonelli e Canêdo Pinheiro, 2017; Bonelli, 2015; Veloso et al., 2014; IEDI, 2018). O crescimento da produtividade na indústria, em geral, não tem um único fator determinante, mas é impactado pelas mudanças estruturais que ocorrem entre os seus setores. Essas mudanças estruturais podem ser classificadas como efeito composição, quando ocorrem deslocamentos de pessoal ocupado entre os setores ou efeito crescimento quando há incremento rápido de produtividade dentro dos setores. A decomposição da produtividade em efeito composição e efeito crescimento indica quais foram os pesos relativos desses fatores no crescimento da produtividade agregada da indústria.

Em particular, quando analisados os efeitos composição e crescimento sobre a evolução da produtividade industrial para os estados brasileiros, notou-se que entre 1995 e 2005, em média, houve uma leve recuperação do crescimento da produtividade dentro dos setores. Nesse mesmo período, o Espírito Santo apresentou um crescimento positivo da produtividade agregada como resultado de uma combinação de efeitos composição e crescimento positivos (Canêdo Pinheiro e Barbosa Filho, 2011). Para o período entre 2003 e 2009, também se observou que o desempenho da produtividade agregada do estado capixaba foi superior ao do Brasil, porém com maior volatilidade. Isso indica que a capacidade da indústria capixaba de gerar ganhos de eficiência entre 2003 e 2009 foi superior à brasileira, porém, a estrutura produtiva do estado se mostrou mais vulnerável a flutuações econômicas do que a brasileira de um ano para o outro (Magalhães e Ribeiro, 2011).

Este estudo tem por objetivo examinar a evolução recente da produtividade do trabalho no Espírito Santo baseado no exemplo de diversos estudos para o Brasil (Canêdo Pinheiro e Barbosa Filho, 2011; Menezes Filho et al., 2014; Veloso et al., 2014; Bonelli, 2015; IEDI, 2018). Busca-se averiguar qual a variação da produtividade para as atividades da indústria de transformação e quais os fatores que explicam o comportamento da produtividade agregada a partir da decomposição shift-share entre os efeitos crescimento e composição entre 2007 e 
2016. Para este fim, o estudo está dividido em cinco seções além desta introdução. Na primeira seção compara-se a estrutura econômica e a evolução da produtividade no Espírito Santo e no Brasil. Na segunda seção descrevem-se as bases de dados utilizadas e a metodologia para o cálculo da produtividade industrial e da decomposição shift-share. A terceira e a quarta seções expõem os resultados e analisam a evolução da produtividade industrial comparando o Espírito Santo com o Brasil e, por fim, a quinta seção apresenta as considerações finais.

\section{Economia e produtividade no Espírito Santo}

Uma das formas de descrever a estrutura econômica do Espírito Santo é pela participação de cada setor no valor adicionado $(\mathrm{VA})^{4}$ e na população ocupada $(\mathrm{PO})^{5}$. Como pode ser visto na tabela 1 , o setor de serviços ocupa a primeira posição em participação no valor adicionado e na população ocupada em 2007 e 2015, para o Espírito Santo e para o Brasil. Neste período, os setores que mais aumentaram suas participações no valor adicionado da economia do Espírito Santo foram administração pública e indústrias extrativas. Entre 2007 e 2015 a participação das indústrias extrativas no valor adicionado do Espírito Santo passou de 0,3\% para $13,0 \%$, valor bastante superior ao observado para o Brasil $(2,1 \%)$. A indústria de transformação do Espírito Santo teve uma queda de participação no VA do estado, passando de 13,3\% em 2007 para 10,5\% em 2015 e na população ocupada, saindo de 12,7\% em 2007 para $10,6 \%$ em 2015. A agropecuária, por sua vez, teve uma queda da participação na população ocupada, passando de 21,2\% em 2007 para 16,2\% em 2015, mas continuou sendo significativamente superior à média nacional. Contudo, a queda da participação da agropecuária no VA capixaba foi muito expressiva, passando de 17,6\% em 2007 para 3,8\% em 2015.

Tabela 1. Participação (\%) dos setores econômicos no valor adicionado e na população ocupada - Espírito Santo e Brasil, 2007 e 2015

\begin{tabular}{|c|c|c|c|c|c|c|c|c|}
\hline \multirow{3}{*}{ Setores do IBGE } & \multicolumn{4}{|c|}{ Valor Adicionado } & \multicolumn{4}{|c|}{ População Ocupada } \\
\hline & \multicolumn{2}{|c|}{2007} & \multicolumn{2}{|c|}{2015} & \multicolumn{2}{|c|}{2007} & \multicolumn{2}{|c|}{2015} \\
\hline & Brasil & $\begin{array}{l}\text { Espírito } \\
\text { Santo }\end{array}$ & Brasil & $\begin{array}{l}\text { Espírito } \\
\text { Santo }\end{array}$ & Brasil & $\begin{array}{l}\text { Espírito } \\
\text { Santo }\end{array}$ & Brasil & $\begin{array}{l}\text { Espírito } \\
\text { Santo }\end{array}$ \\
\hline Administração Pública & 17,9 & 5,1 & 17,2 & 15,8 & 4,9 & 6,1 & 5,2 & 5,5 \\
\hline Agropecuária & 4,6 & 17,6 & 5,0 & 3,8 & 18,5 & 21,2 & 14,1 & 16,2 \\
\hline Comércio & 13,5 & 18,7 & 13,3 & 14,9 & 17,9 & 17,8 & 18,2 & 17,4 \\
\hline Construção & 5,1 & 7,0 & 5,7 & 5,4 & 6,7 & 7,0 & 9,0 & 9,9 \\
\hline $\begin{array}{l}\text { Indústrias de } \\
\text { transformação }\end{array}$ & 15,5 & 13,3 & 12,2 & 10,5 & 14,4 & 12,7 & 11,8 & 10,6 \\
\hline Indústrias extrativas & 1,9 & 0,3 & 2,1 & 13,0 & 0,4 & 1,2 & 0,4 & 1,5 \\
\hline Serviços & 39,0 & 37,4 & 42,0 & 34,5 & 29,1 & 33,7 & 32,2 & 38,4 \\
\hline SIUP & 2,4 & 0,4 & 2,4 & 2,1 & 0,4 & 0,4 & 0,4 & 0,3 \\
\hline
\end{tabular}

Fonte: Contas Nacionais e Regionais; PNAD/IBGE. Elaboração própria.

A relação entre o valor do produto e os insumos necessários para a produção é uma maneira de mensurar a eficiência técnica das empresas produtivas pertencentes a cada setor da economia. Quando essa associação é feita relacionando o valor adicionado (VA) com a quantidade de pessoas ocupadas (PO) no setor, tem-se expressa a produtividade do trabalho. Dessa forma, a produtividade do trabalho equivale ao produto por trabalhador, e quanto maior essa razão, maior a produtividade. Entre 2007 e 2015, a produtividade agregada do Espírito Santo cresceu, em média, 1,3\% ao ano, taxa inferior à registrada pelo país para o mesmo período

\footnotetext{
${ }^{4}$ Os dados foram extraídos a partir do Sistema de Contas Regionais/IBGE para os períodos de 2007 e 2015.

${ }^{5}$ Dados para população ocupada estimados pela Pesquisa por Amostra de Domicílio (PNAD/IBGE) considerando o total de trabalhadores em todas as atividades da economia, inclusive o trabalho informal, sendo assim mais adequado ao cálculo da produtividade do trabalho para a economia como um todo.
} 
(1,4\% ao ano). Na comparação entre 2007 e 2015, o crescimento acumulado da produtividade do Espírito Santo $(11,0 \%)$ foi menor do que o registrado no Brasil $(11,9 \%)$, como visto no gráfico 1.

\section{Gráfico 1. Evolução da produtividade do trabalho na economia - Brasil e Espírito Santo,} 2007-2015 (base: $2007=100$ )

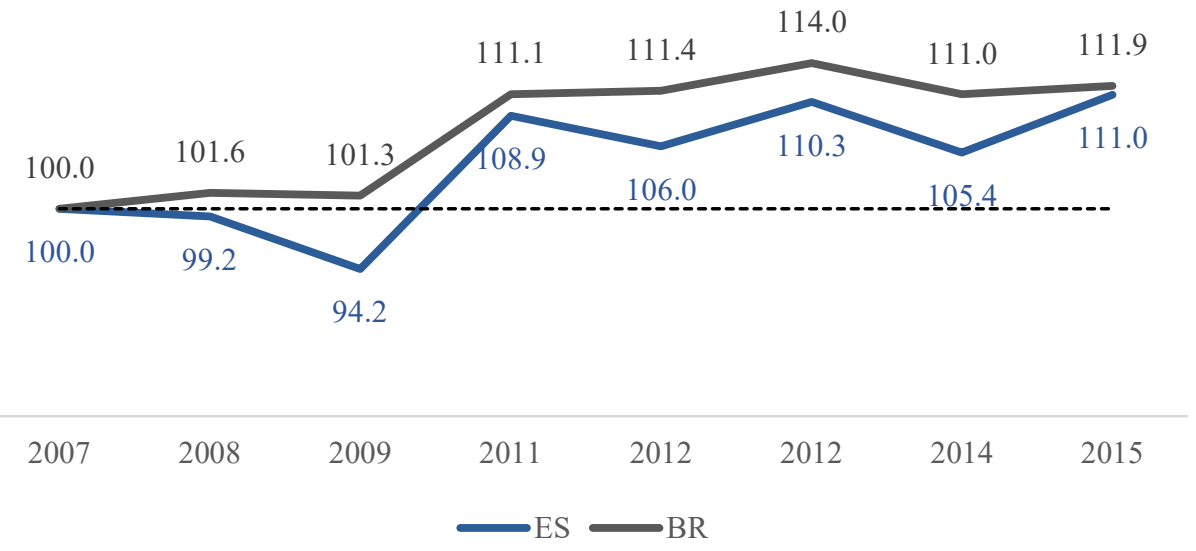

Fonte: Contas Nacionais e Regionais; PNAD/IBGE. Elaboração própria.

O crescimento acumulado da produtividade do trabalho pode ser desagregado por atividades econômicas. No Espírito Santo, de 2007 a 2015, as atividades econômicas com maior crescimento acumulado foram a indústria extrativa $(76,8 \%)$, SIUP $(43,2 \%)$ e agropecuária (31,6\%), vide tabela 2. Dentre os demais setores analisados no período entre 2007 e 2015, a construção $(-13,4 \%)$, comércio $(-8,2 \%)$ e a indústria de transformação $(-8,1 \%)$ apresentaram queda de produtividade. Para o Brasil, no período entre 2007 e 2015, os setores de maior crescimento acumulado da produtividade do trabalho foram: agricultura $(60,1 \%)$, indústria extrativa $(49,0 \%)$ e SIUP $(11,4 \%)$. A construção foi o único setor que registrou uma queda do crescimento médio acumulado para o período $(-5,7 \%)$.

Tabela 2. Crescimento (\%) acumulado da produtividade do trabalho Brasil e Espírito Santo, 2007-2015

\begin{tabular}{l|c|c}
\hline \multicolumn{1}{c|}{ Setores do IBGE } & Brasil & Espírito Santo \\
\hline Administração Pública & 1,2 & 17,7 \\
Agropecuária & 60,1 & 31,6 \\
Comércio & 8,4 & $-8,2$ \\
Construção & $-5,7$ & $-13,3$ \\
Indústrias de transformação & 7,5 & $-8,1$ \\
Indústrias extrativas & 49,0 & 76,8 \\
Serviços & 8,9 & 4,6 \\
SIUP & 11,4 & 43,2 \\
Total & 11,9 & 11,0 \\
\hline
\end{tabular}

Fonte: Contas Nacionais e Regionais; PNAD/IBGE. Elaboração própria.

No Espírito Santo, parte do crescimento expressivo da produtividade do trabalho nas indústrias extrativas é explicado, sobretudo, pelo aumento da exploração de petróleo e gás natural na bacia do pré sal (costa sul do estado), a partir de 2010. Por ser tratar de uma atividade 
intensiva em capital, o impacto do seu crescimento foi significativamente maior sobre o valor da produção do que para o incremento da quantidade de pessoas ocupadas, ocasionando assim um grande aumento na produtividade do trabalho.

A comparação do crescimento anual da produtividade da indústria de transformação do Espírito Santo com o do Brasil entre 2007 e 2015 mostrou diferenças significativas, como notase no gráfico 2. Em 2008 e 2011, a taxa de crescimento da produtividade da indústria de transformação do Espírito Santo foi superior à do Brasil. Porém, desde a queda da taxa de crescimento em 2012, a indústria capixaba não conseguiu recuperar o mesmo de nível de produtividade do início da sua série em 2007. O Brasil, embora também tenha apresentado uma queda da taxa de crescimento anual em 2012, conseguiu manter o seu nível de produtividade acima do valor inicial de 2007.

\section{Gráfico 2. Evolução da produtividade do trabalho na indústria de transformação - Brasil e} Espírito Santo, 2007-2015 (base: $2007=100$ )

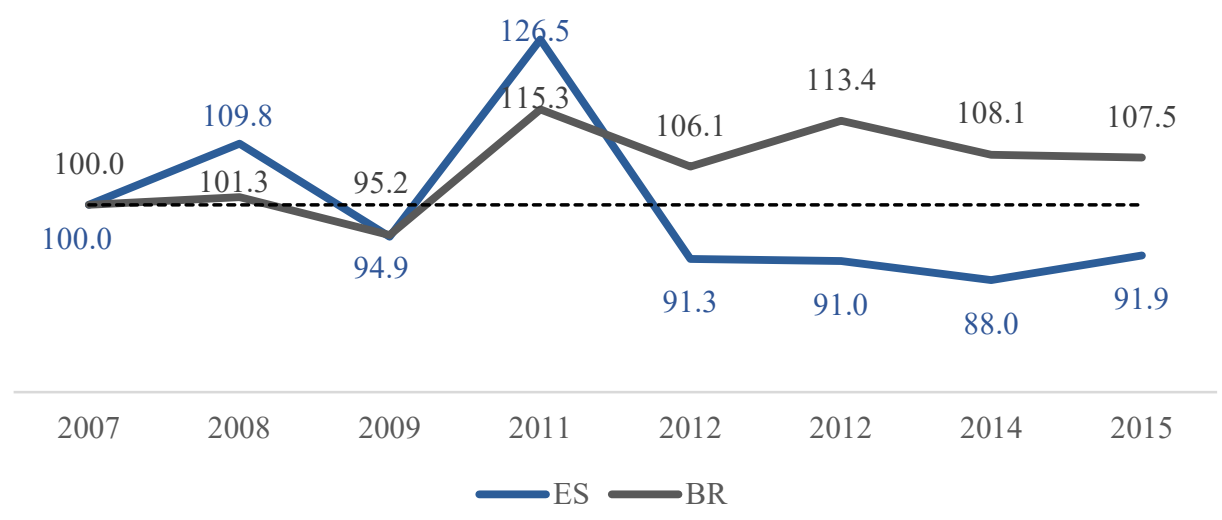

Fonte: Contas Nacionais e Regionais; PNAD/IBGE. Elaboração própria.

\section{Bases de dados e metodologia}

Os dados utilizados para o cálculo da produtividade da indústria de transformação e de seus setores são diferentes daqueles utilizados para o cálculo da produtividade das atividades econômicas na seção anterior. Embora seja possível mensurar a produtividade do trabalho na indústria da transformação a partir da razão entre a medida do valor adicionado e do número de trabalhadores, para analisar a produtividade dos diversos setores da indústria de transformação foi necessário utilizar os dados do Valor da Transformação Industrial (VTI) ${ }^{6}$ e da População Ocupada (PO) fornecidos pela Pesquisa Industrial Anual (PIA-Empresa/IBGE) ${ }^{7}$. Essa mudança metodológica justifica-se porque a primeira forma permite comparar a indústria de transformação com as demais atividades econômicas, mas somente a segunda permite uma comparação entre os setores da indústria de transformação de forma desagregada.

\footnotetext{
${ }^{6} \mathrm{O}$ Valor da Transformação Industrial (VTI) corresponde ao montante, expresso em valores correntes que foi acrescido à matéria prima, representando a capacidade da indústria em transformar matéria-prima em produto industrial.

${ }^{7}$ Os dados da PIA foram extraídos da tabela de dados gerais das unidades locais industriais de empresas industriais com 5 ou mais pessoas ocupadas, segundo as Grandes Regiões e as Unidades da Federação (IBGE, 2018).
} 
Para o cálculo da produtividade do trabalho da indústria de transformação agregada e para os seus setores foi feita a divisão do valor da transformação industrial (VTI) real $^{8}$ pela quantidade de pessoas ocupadas (PO), tal que:

$$
\mathrm{PT}_{i t}=\frac{\mathrm{VTI}_{\mathrm{it}}}{\mathrm{PO}_{\text {it }}}
$$

Em que a produtividade do trabalho, PT, é dada pela relação entre o valor da transformação industrial, VTI, e o pessoal ocupado, PO, no setor $i$ no ano $t$. As séries de VTI e PO para o Espírito Santo foram extraídas segundo a Classificação Nacional de Atividades Econômicas (CNAE 2.0), a dois dígitos, para o período de 2007 a 2016 (PIA-Empresa /IBGE).

A produtividade relativa é dada pela razão entre as produtividades de duas regiões distintas. Essa divisão capta o quanto maior ou menor está a produtividade da região em relação ao país. Ela é calculada da seguinte maneira:

$$
\mathrm{PR}_{i t}=\frac{V T I_{i t}^{E S}}{P O_{i t}^{E S}} / \frac{V T I_{i t}^{B R}}{P O_{i t}^{B R}}
$$

Tal que, a produtividade relativa, PR, é dada pela relação entre VTI e PO do Espírito Santo (ES) na atividade i no ano t dividida pela relação entre VTI e PO do Brasil (BR) ${ }^{9}$ na atividade $i$ no ano $t$. Quando a produtividade relativa é maior que 1, a atividade é mais produtiva no Espírito Santo do que no Brasil e quando é menor que 1, a atividade no estado está menos produtiva do que no resto do país.

O crescimento da produtividade pode ser decomposto por meio do shift-share em dois efeitos: efeito composição e efeito crescimento (Canêdo Pinheiro e Barbosa Filho, 2011; Bonelli, 2014; Menezes Filho et al., 2014). Essa decomposição indica os pesos relativos que as transformações tecnológicas e a mudança estrutural têm sobre o crescimento da produtividade do trabalho. $\mathrm{O}$ efeito crescimento se refere a variações na produtividade agregada, mantendo inalterada a composição da população ocupada. Em paralelo, o efeito composição, considera a mudança na produtividade dada pela transferência de pessoal ocupado entre os setores mantida a estrutura produtiva.

A decomposição da taxa de crescimento da produtividade é calculada como:

$$
\frac{\Delta Y_{t}}{Y_{0}}=\overbrace{\sum_{i=1}^{I}\left(\frac{\Delta Y_{i t}}{Y_{0}} \times \bar{p}_{l}\right)}^{\text {Efeito crescimento }}+\overbrace{\sum_{i=1}^{I}\left(\frac{\bar{Y}_{l}}{Y_{0}} \times \Delta p_{i t}\right)}^{\text {Efeito composição }}
$$

Em que:

$$
\begin{aligned}
& \Delta Y_{i t}=\left(Y_{i t}-Y_{i 0}\right) ; \\
& \Delta p_{i t}=\left(p_{i t}-p_{i 0}\right) ; \\
& \bar{p}_{\iota}=\frac{p_{i t}+p_{i 0}}{2}
\end{aligned}
$$

\footnotetext{
${ }^{8}$ O VTI é expresso em unidade monetária (R\$) e em valores correntes. Para este trabalho, foi criado um deflator implícito com base no índice da produção física da indústria (PIM-PF) acumulado no ano e, assim, utilizando o VTI a preços reais (Bonelli e Canêdo Pinheiro, 2017).

${ }^{9}$ Excluindo-se o Espírito Santo.
} 


$$
\bar{Y}_{l}=\frac{Y_{i t}+Y_{i 0}}{2}
$$

Tal que $i$ identifica o setor, 0 indica o período inicial, $t$ indica o período corrente, $Y$ é o valor da produtividade do trabalho, $\Delta Y_{i t} / Y_{0}$ é a taxa de variação da produtividade e $p$ é a participação do pessoal ocupado no período em análise.

Em síntese, o efeito crescimento da produtividade do trabalho é dado pelo produto entre a variação da produtividade e a média de participações do pessoal ocupado. Já o efeito composição é resultante do produto entre a média da produtividade e a variação da participação do pessoal ocupado entre o período inicial e o período final da análise.

\section{Produtividade do trabalho na indústria do Espírito Santo}

O gráfico 3 apresenta a evolução da produtividade do trabalho na indústria do Espírito Santo e das variáveis que compõem o seu cálculo, o valor da transformação industrial e a população ocupada. Considerando 2007 como ano base, o VTI da indústria de transformação do Espírito Santo tem apresentado um comportamento volátil, alternando períodos de crescimento e de queda. Apenas em 2010 o valor da transformação industrial do estado superou o patamar do início da série (2007). Na comparação de 2016 contra 2007, o VTI apresentou uma queda de 5,4\%. Por outro lado, a população ocupada (PO) na indústria de transformação do Espírito Santo apresentou uma trajetória ascendente até 2014, como nota-se no gráfico 3. A produtividade, resultante da relação entre VTI e PO, de 2007 a 2016 teve queda acumulada de $12,6 \%$. Essa retração da produtividade do trabalho no Espírito Santo é explicada tanto pela redução no VTI do setor (-0,5\% a.a.) quanto pelo aumento médio da PO ( $+0,8 \%$ a.a.) durante os anos estudados.

\section{Gráfico 3. Indústria de Transformação do Espírito Santo: valor da transformação industrial, emprego e produtividade, 2007-2016 (base: $2007=100$ )}

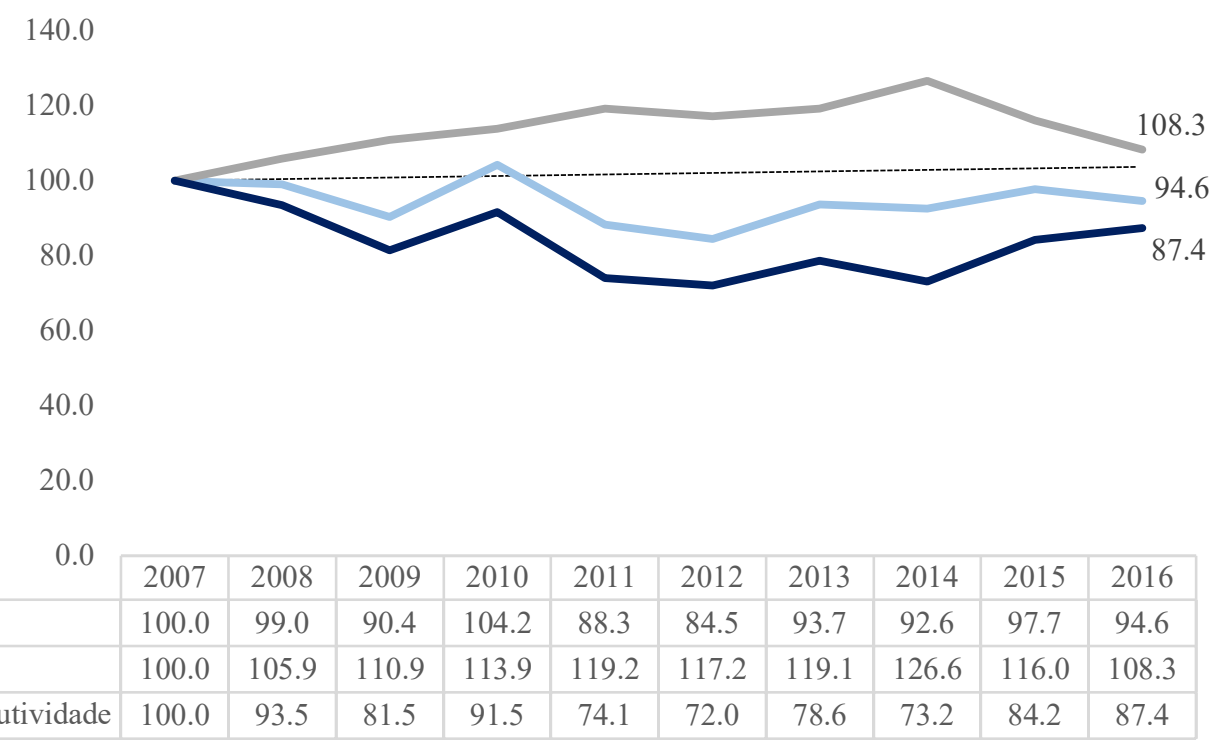

Fonte: PIA-Empresa/IBGE. Elaboração própria.

Com a desaceleração da economia brasileira, que teve início no ano de 2014, houve um aumento no desemprego em todo país, reduzindo também o número de pessoas empregadas na indústria. Mesmo com essa redução conjuntural, o tamanho da população ocupada no Espírito 
Santo se manteve acima do seu nível registrado no início da série, com uma taxa de crescimento acumulado de $8,3 \%$ entre 2007 e 2016.

Para uma melhor compreensão da evolução do valor de transformação industrial e da população ocupada no Espírito Santo entre 2007 e 2016, esses dados foram desagregados por setor. No gráfico 4 estão os setores de maior participação no VTI do Espírito Santo entre 2007 e 2016: metalurgia, celulose e papel, minerais não-metálicos e alimentos. Neste período, a participação dos outros setores foi resultante, sobretudo, da queda de metalurgia e de minerais não-metálicos.

Gráfico 4. Participação (\%) dos principais setores no VTI - Espírito Santo, 2007-2016 Fonte: PIA-Empresa/IBGE. Elaboração própria.

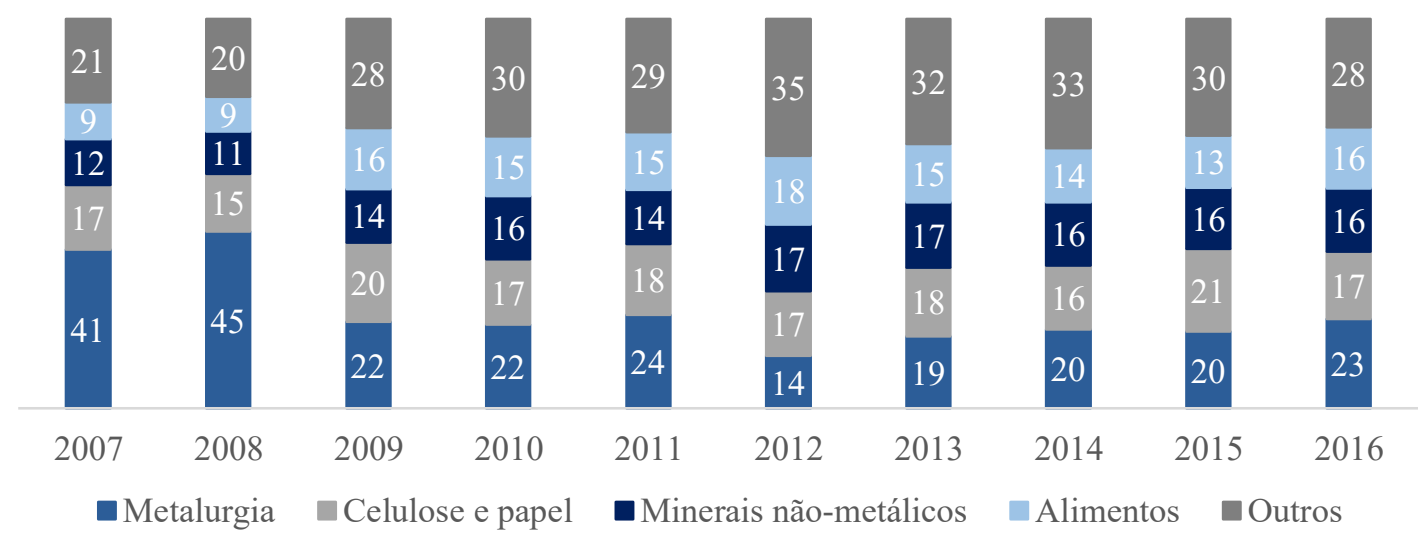

No gráfico 5 estão os setores de maior participação na população ocupada da indústria capixaba entre 2007 e 2016: minerais não-metálicos, alimentos, vestuário e metalurgia. Os setores de metalurgia, minerais não-metálicos e alimentos possuem uma participação muito relevante tanto no valor da transformação industrial, quanto na população ocupada do Espírito Santo. O setor de minerais não-metálicos aumentou sua participação no VTI e manteve participação estável na PO e o setor de alimentos aumentou sua participação no VTI e na PO. A metalurgia apresentou uma queda significativa de participação no VTI da indústria entre 2007 e 2016, porém sua participação no total da população ocupada permaneceu estável.

\section{Gráfico 5. Participação (\%) dos principais setores na PO - Espírito Santo, 2007-2016}

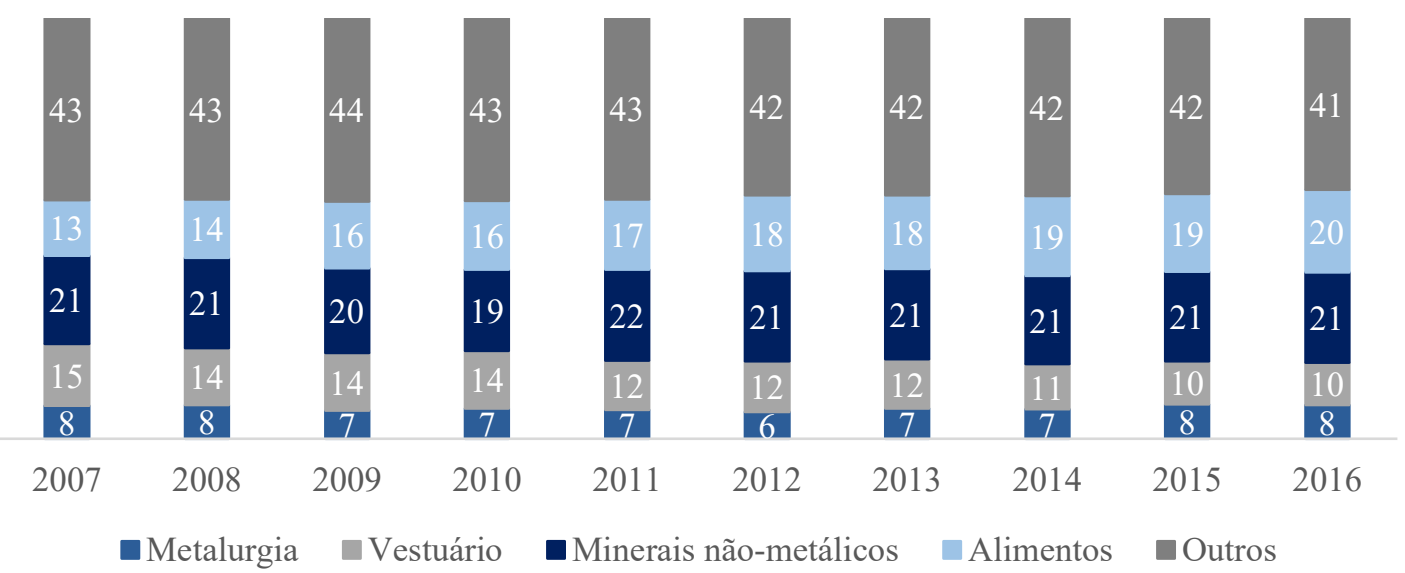


Fonte: PIA-Empresa/IBGE. Elaboração própria.

Considerando a evolução das variáveis de VTI e PO entre 2007 e 2016, neste período houve queda da produtividade do trabalho na indústria de transformação tanto no Espírito Santo, quanto no Brasil. No gráfico 6 observa-se pela evolução anual do índice de produtividade que a trajetória do Espírito Santo foi muito semelhante à do Brasil. Entre 2007 e 2016 a produtividade brasileira variou em média $-1,5 \%$ ao ano e apresentou uma taxa de crescimento acumulada de $-14,3 \%$. Para o mesmo período, o Espírito Santo apresentou taxas de crescimento médio de $-1,3 \%$ ao ano, o que resultou em uma queda acumulada entre 2007 e 2016 de $-12,6 \%$.

\section{Gráfico 6. Evolução da produtividade do trabalho na indústria de transformação - Espírito Santo e Brasil, 2007-2016 (base: 2007 = 100)}

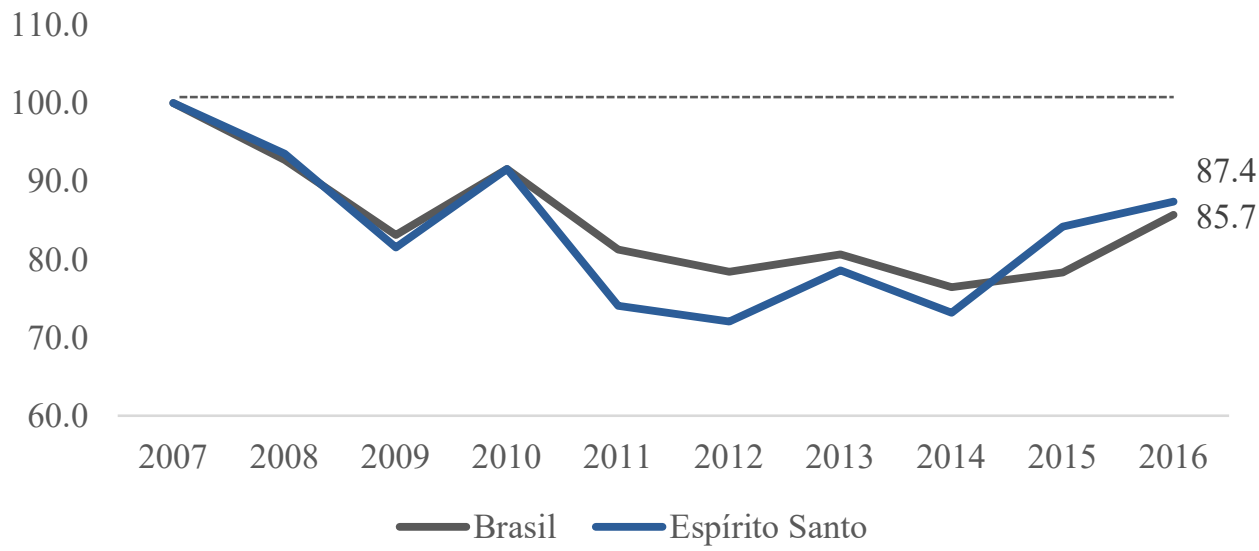

Fonte: PIA-Empresa/IBGE. Elaboração própria.

Com o objetivo de comparar o desempenho individual dos $21^{10}$ setores industrias do Espírito Santo com os do Brasil, os dados de variação da produtividade da indústria entre 2007 e 2016 foram desagregados, como se pode observar no gráfico 7. As cores dos pontos identificam quatro tipos de comportamento dos setores da indústria capixaba: azul claro indica crescimento da produtividade, porém, inferior ao do Brasil; cinza claro indica crescimento da produtividade superior ao do Brasil; cinza escuro indica que houve queda da produtividade e azul escuro indica queda da produtividade e desempenho pior que o do Brasil. O Espírito Santo teve nove setores com desempenho de produtividade maior que o do Brasil entre 2007 e 2016, representados pelos pontos na cor cinza claro no gráfico 7. O setor de alimentos, em azul claro, foi o que apresentou a maior taxa de variação da produtividade entre 2007 e 2016 para o Espírito Santo $(+4,3 \%)$ e para o Brasil $(+4,9 \%)$. A metalurgia apresentou a maior queda de produtividade na indústria do Brasil $(-4,1 \%)$ e do Espírito Santo $(-20,5 \%)$.

\footnotetext{
${ }^{10}$ Os dados do VTI para os setores em que o número de informantes é inferior a 3 não são divulgados pelo IBGE com o intuito de não identificar as empresas que responderam à pesquisa. No caso do Espírito Santo, não foram divulgados os dados completos para o período de 2007 a 2016 das divisões 12, 21 e 26 (CNAE 2.0), referentes a fabricação de produtos de fumo, a fabricação de produtos farmoquímicos e de fabricação de equipamentos de informática, produtos eletrônicos e ópticos, respectivamente.
} 


\section{Gráfico 7. Variação (\%) da produtividade agregada por setores - Brasil e Espírito Santo, 2007-2016}

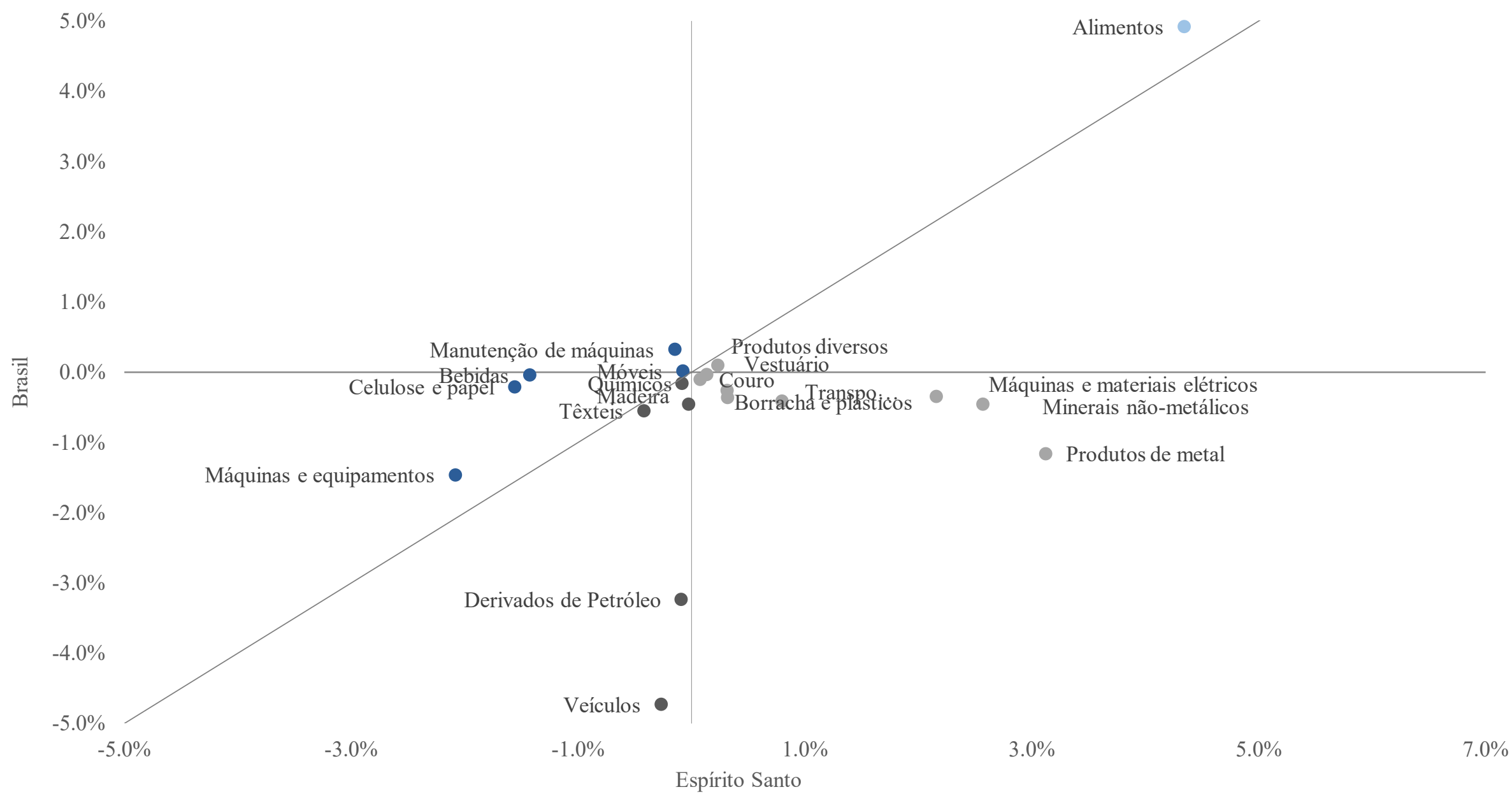

Fonte: PIA-Empresa/IBGE. Elaboração própria. 
Na tabela 3 estão os setores que tiveram maior crescimento acumulado da produtividade do trabalho no Espírito Santo de 2007 a 2016, foram eles: produtos de metal, produtos diversos, vestuário, borracha e material plástico, impressão e gravações, transporte e derivados de petróleo. Dentre esses setores, apenas produtos de metal e vestuário estão entre aqueles com maior participação no VTI e na PO e, portanto, têm uma influência maior sobre o índice geral da produtividade do estado. Os setores com as menores taxas acumuladas de crescimento no mesmo período foram bebidas, metalurgia, têxteis e máquinas e equipamentos. Os três últimos setores tiveram queda de participação tanto no VTI como na PO da indústria de transformação entre 2007 e 2016.

Tabela 3. Crescimento (\%) acumulado da produtividade em atividades industriais - Espírito Santo, 2007-2016

\begin{tabular}{|c|c|c|c|}
\hline & & $\begin{array}{l}\text { Crescimento } \\
\text { Acumulado }\end{array}$ & $\begin{array}{l}\text { Taxa média de } \\
\text { crescimento anual }\end{array}$ \\
\hline \multirow{7}{*}{ 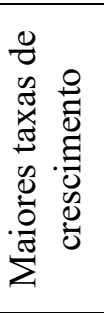 } & Produtos de metal & 97,9 & 7,9 \\
\hline & Produtos diversos & 92,3 & 7,5 \\
\hline & Vestuário & 58,6 & 5,3 \\
\hline & Borracha e material plástico & 53,4 & 4,9 \\
\hline & Impressão e gravações & 46,7 & 4,4 \\
\hline & Transporte & 38,8 & 3,7 \\
\hline & Derivados de Petróleo & 35,6 & 3,4 \\
\hline \multirow{8}{*}{ 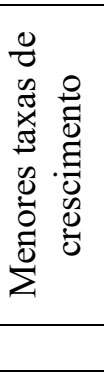 } & Manutenção de máquinas & $-3,8$ & $-0,4$ \\
\hline & Produtos químicos & $-28,1$ & $-3,6$ \\
\hline & Veículos & $-32,2$ & $-4,2$ \\
\hline & Máquinas e equipamentos & $-41,1$ & $-5,7$ \\
\hline & Têxteis & $-46,2$ & $-6,7$ \\
\hline & Metalurgia & $-51,7$ & $-7,8$ \\
\hline & Bebidas & $-61,8$ & $-10,1$ \\
\hline & Indústria de Transformação & $-12,6$ & $-1,3$ \\
\hline
\end{tabular}

Fonte: PIA-Empresa/IBGE. Elaboração própria.

Outra forma de examinar a evolução da produtividade do trabalho na indústria capixaba é comparar seu desempenho em relação ao do Brasil por meio da produtividade relativa definida na seção 2 . No gráfico 8 observam-se as trajetórias da produtividade relativa da indústria geral, que considera as indústrias de transformação e extrativas, e da indústria de transformação entre 2007 e 2016. O Espírito Santo obteve produtividade relativa na indústria geral superior à brasileira para todo o período. Enquanto que, analisando a produtividade relativa da indústria de transformação, o desempenho do setor no Espírito Santo foi inferior ao nacional, com exceção apenas do ano de 2015. Portanto, pode-se inferir que a produtividade da indústria geral no estado somente foi superior à do país no período analisado devido ao desempenho relativo das suas indústrias extrativas. 


\section{Gráfico 8. Evolução da produtividade relativa da indústria - Espírito Santo, 2007- 2016}

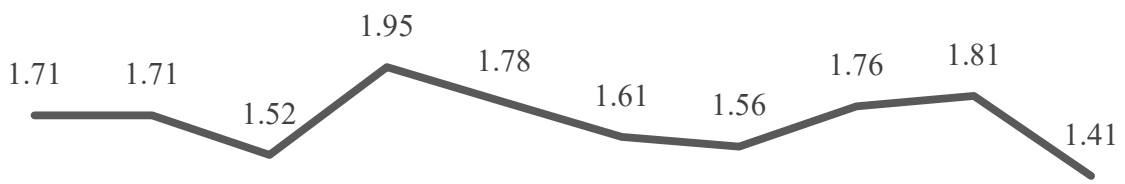

$\mathrm{ES}=\mathrm{BR}$, Produtividade relativa $=1$

\begin{tabular}{|c|c|c|c|c|c|c|c|c|c|}
\hline 0.97 & 0.98 & 0.95 & 0.97 & 0.88 & 0.89 & 0.94 & 0.93 & 1.04 & 0.99 \\
\hline 2007 & 2008 & 2009 & 2010 & 2011 & 2012 & 2013 & 2014 & 2015 & 2016 \\
\hline
\end{tabular}

Fonte: PIA-Empresa/IBGE. Elaboração própria.

Os setores da indústria da transformação do Espírito Santo que apresentaram as maiores produtividades relativas em 2016 foram: celulose e papel, metalurgia e produtos de metal, que podem ser observadas na tabela 4. Em 2007, dos 24 setores da indústria de transformação analisados, apenas dois foram relativamente mais produtivos no estado do que no Brasil: celulose e papel e metalurgia. Enquanto que em 2016 essa lista aumentou incluindo também os setores de produtos de metal, minerais não-metálicos e máquinas e materiais elétricos. $\mathrm{Na}$ tabela 4 também estão as atividades com as menores produtividades relativas em 2016: coque e derivados de petróleo, veículos, têxteis, máquinas e equipamentos e bebidas.

Tabela 4. Produtividade relativa das atividades da indústria de transformação Espírito Santo, 2007/2016

\begin{tabular}{|c|c|c|c|}
\hline & & 2007 & 2016 \\
\hline \multirow{5}{*}{ 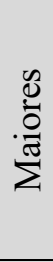 } & Celulose e papel & 5,09 & 6,37 \\
\hline & Metalurgia & 1,96 & 1,50 \\
\hline & Produtos de metal & 0,56 & 1,36 \\
\hline & Minerais não-metálicos & 0,81 & 1,27 \\
\hline & Máquinas e materiais elétricos & 0,79 & 1,04 \\
\hline \multirow{5}{*}{$\begin{array}{l}\stackrel{0}{0} \\
\stackrel{0}{0} \\
\sum^{0}\end{array}$} & Bebidas & 1,05 & 0,48 \\
\hline & Máquinas e equipamentos & 0,62 & 0,46 \\
\hline & Têxteis & 0,56 & 0,33 \\
\hline & Veículos & 0,24 & 0,26 \\
\hline & Derivados de Petróleo & 0,10 & 0,17 \\
\hline & Indústria da transformação & 0,97 & 0,99 \\
\hline
\end{tabular}

Fazendo um paralelo entre as tabelas 3 e 4 e comparando os resultados de crescimento acumulado da produtividade e da produtividade relativa, é interessante notar que a metalurgia apresentou a menor taxa de crescimento acumulada de produtividade no Espírito Santo entre 2007 e 2016, mas ainda possui uma produtividade relativa superior à unidade. Isso revela que, embora o setor de metalurgia capixaba tenha acumulado queda 
de produtividade no período analisado, quando comparado ao Brasil, ele ainda é mais produtivo. A fabricação de produtos de metal, por sua vez, teve o maior crescimento acumulado no estado $(+97,9 \%)$ e também aumentou sua produtividade relativa neste período, o que significa que a produtividade deste setor cresceu mais no estado do que no resto do país. As atividades de menor produtividade relativa do estado, como fabricação de derivados de petróleo, veículos, têxteis, máquinas e equipamentos, apresentaram queda da sua participação no VTI e na PO da indústria de transformação e cresceram pouco, de acordo com a tabela 3. Já o setor de derivados de petróleo do Espírito Santo, que teve uma taxa elevada de crescimento acumulado (+35,6\%) entre 2007 e 2016 (tabela 3), ainda possui uma produtividade muito baixa se comparada ao resto do país (tabela 4).

\section{Decomposição do Desempenho da Produtividade do Trabalho}

A decomposição da variação da produtividade do Espírito Santo e do Brasil busca averiguar qual foi o efeito, se de composição ou de crescimento, que mais contribuiu para o desempenho das atividades industriais.

Conforme se observa na tabela 5 , a variação da produtividade agregada da indústria no Espírito Santo entre 2007 e 2016 foi de -12,6\%, enquanto que a brasileira foi de $-14,3 \%$. A variação da produtividade agregada decorre da soma de dois efeitos: composição e crescimento, ambos apresentados na tabela 5. O efeito composição, que ocorre pela variação de emprego entre os setores, foi positivo em 1,9\% no Espírito Santo e negativo em 0,3\% para o Brasil entre 2007 e 2016. Enquanto que o efeito crescimento, que reflete o crescimento de produtividade dentro dos setores mantendo constante a composição da PO, foi de -14,5\% para o Espírito Santo e de -14,1\% para o Brasil.

Tabela 5. Decomposição da variação (\%) da produtividade da indústria da transformação - Espírito Santo e Brasil, 2007-2016

\begin{tabular}{lccc}
\hline & $\begin{array}{c}\text { Efeito crescimento } \\
\text { (a) }\end{array}$ & $\begin{array}{c}\text { Efeito composição } \\
\text { (b) }\end{array}$ & $\begin{array}{c}\text { Produtividade agregada } \\
(\mathrm{a}+\mathrm{b})\end{array}$ \\
\hline Espírito Santo & $-14,51$ & 1,87 & $-12,65$ \\
Brasil & $-14,06$ & $-0,27$ & $-14,33$ \\
\hline
\end{tabular}

Fonte: PIA-Empresa/IBGE. Elaboração própria.

Essa queda de produtividade da indústria não foi um fenômeno generalizado entre os setores. Como observado na seção anterior, em alguns setores houve crescimento entre 2007 e 2016 (gráfico 7). Os quadros 1 e 2 apresentam os resultados da decomposição shift-share da produtividade separando os setores pelo sinal dos seus efeitos composição e crescimento. A soma dos efeitos composição e crescimento pode ter resultado positivo ou negativo dependendo do sinal e da magnitude de cada parcela.

Para o Brasil, a produtividade agregada entre 2007 e 2016 foi impactada com maior intensidade pelos setores que tiveram efeito crescimento negativo (dados no anexo 4). Em paralelo, dos quatro setores que registraram aumento de produtividade, destacados em negrito no quadro 1, o efeito composição foi maior do que o efeito crescimento, exceto para móveis. Em síntese, a variação negativa da produtividade na indústria brasileira entre 2007 e 2016 foi mais explicada pelo efeito de crescimento intrassetorial da produtividade do que pela migração de trabalhadores entre os setores. 
Quadro 1. Comparativo da decomposição shift-share - Brasil, 2007-2016

\begin{tabular}{|c|c|c|c|}
\hline \multirow{4}{*}{ 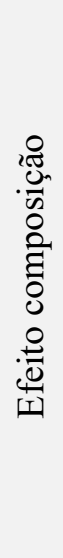 } & \multicolumn{3}{|c|}{ Efeito crescimento } \\
\hline & & Negativo & Positivo \\
\hline & 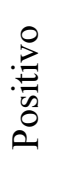 & $\begin{array}{l}\text { Bebidas; Produtos químicos; Produtos farmoquímicos; } \\
\text { Minerais não-metálicos; Equipamentos de transporte e } \\
\text { Produtos diversos }\end{array}$ & $\begin{array}{l}\text { Alimentos e } \\
\text { Manutenção de } \\
\text { máquinas e } \\
\text { equipamentos }\end{array}$ \\
\hline & 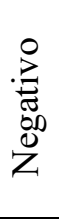 & $\begin{array}{l}\text { Fumo; Têxteis; Vestuário; Madeira; Celulose e papel; } \\
\text { Impressão e gravações; Derivados de Petróleo; Produtos de } \\
\text { borracha e material plástico; Metalurgia; Produtos de metal; } \\
\text { Informática; Máquinas e materiais elétricos; Máquinas e } \\
\text { equipamentos e Veículos }\end{array}$ & Móveis e Couro \\
\hline
\end{tabular}

Fonte: PIA-Empresa/IBGE. Elaboração própria.

O Espírito Santo teve mais setores alocados no quadrante de efeito composição e efeito crescimento positivos do que o Brasil, isso quer dizer que o estado teve mais setores com ganhos de produtividade agregada entre 2007 e 2016. São vários os setores capixabas que obtiveram um crescimento da produtividade positivo resultante da soma dos dois efeitos, esses setores estão destacados em negrito no quadro 2 (dados no anexo 3). Ainda que no Espírito Santo diversos setores tenham apresentado ganhos de produtividade, a combinação de efeito composição positivo de $0,9 \%$ e efeito crescimento negativo de $21,4 \%$ da metalurgia impactou fortemente a variação da produtividade agregada do estado. Em geral, os ganhos de produtividade dos setores industriais no Espírito Santo foram mais relacionados ao efeito crescimento do que ao efeito composição.

Quadro 2. Comparativo da decomposição shift-share - Espírito Santo, 2007-2016

\begin{tabular}{|c|c|c|c|}
\hline \multirow{4}{*}{ 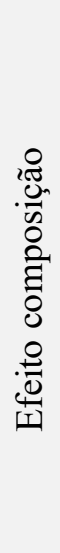 } & \multicolumn{3}{|c|}{ Efeito crescimento } \\
\hline & \multicolumn{2}{|r|}{ Negativo } & Positivo \\
\hline & 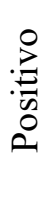 & $\begin{array}{c}\text { Alimentos; Bebidas; Produtos } \\
\text { químicos e Metalurgia }\end{array}$ & $\begin{array}{l}\text { Minerais não-metálicos; Produtos de metal; } \\
\text { Produtos diversos; Equipamentos de } \\
\text { transporte; Máquinas e materiais elétricos e } \\
\text { Impressão e gravações }\end{array}$ \\
\hline & 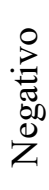 & $\begin{array}{l}\text { Têxteis; Máquinas e } \\
\text { equipamentos; Veículos e } \\
\text { Manutenção de máquinas e } \\
\text { equipamentos }\end{array}$ & $\begin{array}{c}\text { Vestuário; Couro; Madeira; Celulose e papel; } \\
\text { Derivados de Petróleo; Produtos de borracha e } \\
\text { material plástico e Móveis }\end{array}$ \\
\hline
\end{tabular}

Fonte: PIA-Empresa/IBGE. Elaboração própria.

No gráfico 9, os pontos representam as diferentes atividades da indústria da transformação - em vermelho para o Brasil e em azul para o Espírito Santo - posicionadas de acordo com o peso dos efeitos crescimento e composição sobre sua produtividade agregada. O efeito composição é dado pela posição superior ou inferior no gráfico, enquanto o efeito crescimento está relacionado ao lado esquerdo se negativo e ao lado direito quando positivo. Os pontos vermelhos, que representam os setores da indústria para o Brasil, estão mais concentrados do lado esquerdo do gráfico, o que indica que o efeito crescimento foi predominantemente negativo. Para o Espírito Santo, a maioria dos setores, representados pelos pontos em azul, está posicionada do lado direito do gráfico, indicando predomínio do efeito crescimento positivo. 
A proximidade dos pontos à reta de $45^{\circ}$, no gráfico 9 , indica que a variação da produtividade na maioria das indústrias foi equilibrada entre o valor do efeito composição e do efeito crescimento. Acima da reta de $45^{\circ}$ estão todos os setores com efeito composição maior do que efeito crescimento, neste caso, a indústria de fabricação de alimentos foi a que obteve a maior variação positiva do efeito composição tanto para o Espírito Santo $(+4,7 \%)$, quanto para o Brasil $(+3,5 \%)$. Abaixo da reta de $45^{\circ}$, todos os setores têm um efeito crescimento superior ao efeito composição. Para o Espírito Santo, os setores com maior efeito crescimento foram celulose e papel $(+3,4 \%)$, produtos de metal $(+2,5 \%)$ e minerais não-metálicos $(+2,3 \%)$. Para o Brasil, entre todas as atividades industriais, o setor de alimentos apresentou a maior variação do efeito crescimento, com $1,4 \%$.

\section{Gráfico 9. Decomposição shift-share da produtividade - Brasil e Espírito Santo, 2007-2016 ${ }^{11}$}

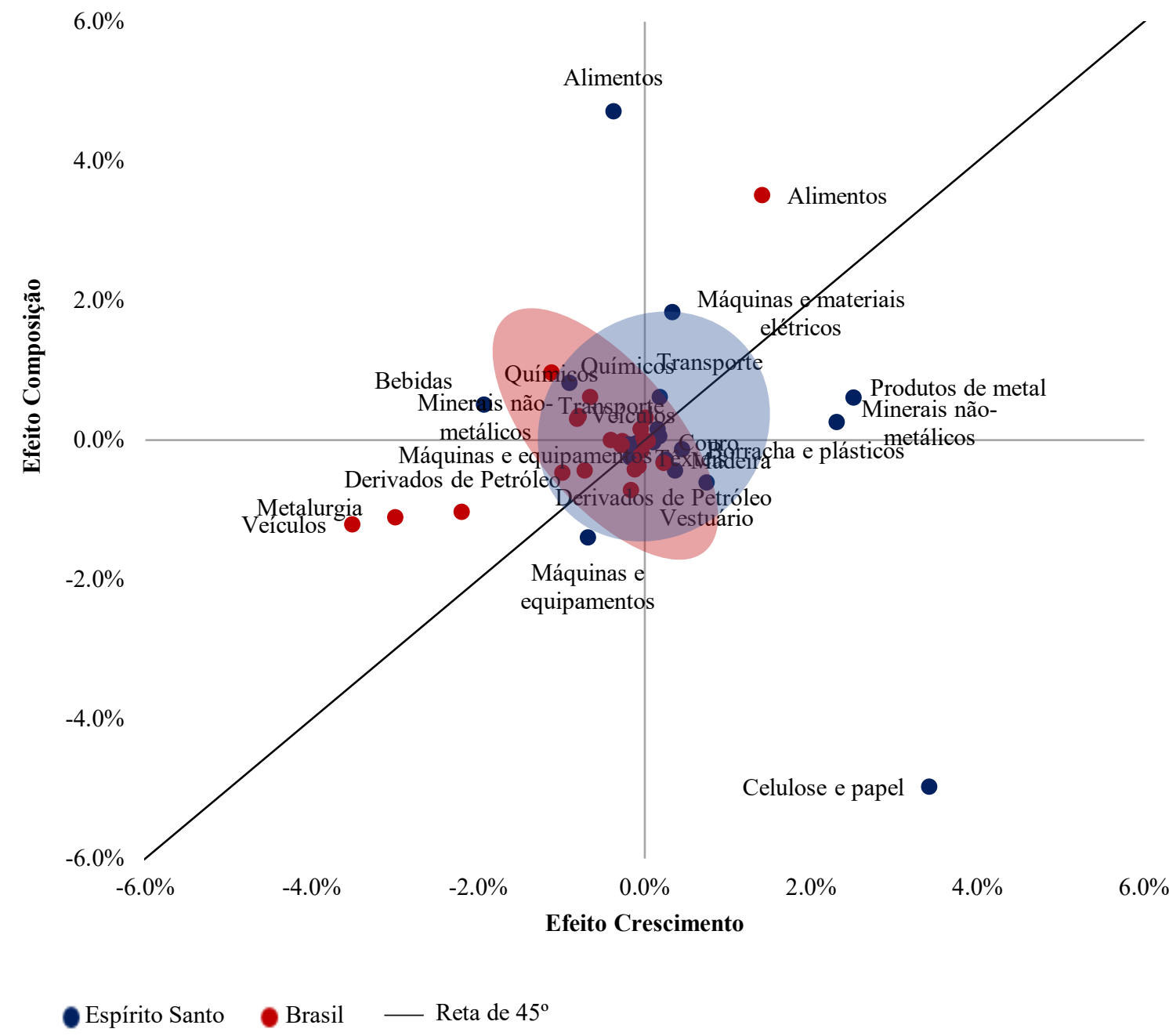

Fonte: PIA-Empresa/IBGE. Elaboração própria.

A evolução da produtividade das principais atividades industriais do Espírito Santo, em termos da participação no VTI e na PO é detalhada a seguir:

\footnotetext{
${ }^{11}$ A atividade de metalurgia do Espírito Santo não foi representada no gráfico 9 porque registrou um valor muito inferior à média dos demais setores industriais.
} 
- Alimentos foi a atividade que obteve a maior variação positiva no período 2007-2016, com 4,3\%, sendo decomposto em - $0,4 \%$ de efeito crescimento e $4,7 \%$ em efeito composição. Cabe destacar que a variação na produtividade geral da atividade foi predominantemente um resultado da migração de trabalhadores entre setores;

- Celulose e papel teve queda da produtividade de $-1,6 \%$, resultante de um aumento do efeito crescimento de $3,4 \%$ e de uma queda do efeito composição de $-5,0 \%$;

- Metalurgia registrou a maior queda da produtividade agregada da indústria do estado (-20,5\%). Esta variação pode ser decomposta em $-21,4 \%$ de efeito crescimento e $0,9 \%$ de efeito composição. Este setor teve a maior participação no VTI do Espírito Santo em 2016 (23,2\%) e isso exerceu grande influência na variação da produtividade industrial agregada do estado;

- Minerais não-metálicos obteve crescimento da produtividade agregada de $2,6 \%$ entre 2007 e 2016 resultante de efeito crescimento de $2,3 \%$ e efeito composição de $0,3 \%$.

\section{Considerações finais}

A estrutura econômica do Espírito Santo passou por mudanças significativas entre 2007 e 2015 com o crescimento da participação das indústrias extrativas no valor adicionado e na população ocupada. A contribuição das atividades da administração pública e do SIUP para o valor adicionado também aumentou, enquanto os setores da agropecuária, da indústria de transformação e do comércio perderam participação no VA e na PO. Em parte, essa mudança na estrutura econômica é explicada pela expansão da exploração de petróleo e gás natural na bacia do Pré-sal (costa sul do estado), a partir de 2010, aumentando a participação das indústrias extrativas no valor adicionado do Espírito Santo. Esta atividade também contribuiu para o crescimento expressivo da produtividade do trabalho das indústrias extrativas observado no estado, por ser tratar de uma atividade intensiva em capital. A agropecuária, por sua vez, mesmo perdendo participação na estrutura econômica, apresentou ganhos significativos de produtividade para o período de 2007 a 2015. Dadas essas mudanças, o crescimento da produtividade do trabalho agregada no Espírito Santo foi de $11,0 \%$ neste período, valor este um pouco inferior à taxa alcançada pelo país, de $11,9 \%$.

A produtividade da indústria de transformação do Espírito Santo, medida pela relação entre o valor da transformação industrial e a população ocupada, apresentou retração entre 2007 e 2016 de 12,6\%. Esse resultado é explicado tanto pela redução no VTI desta indústria (-0,5\% a.a.) quanto pelo aumento médio da PO ( $+0,8 \%$ a.a.) durante os anos estudados. Essa evolução do índice de produtividade da indústria de transformação do Espírito Santo foi muito semelhante à do Brasil, que também observou queda desse índice de $14,3 \%$.

A queda de produtividade da indústria de transformação capixaba não foi um fenômeno generalizado entre os setores. Como visto, os setores que tiveram maior crescimento acumulado da produtividade do trabalho no Espírito Santo de 2007 a 2016, foram: produtos de metal, produtos diversos, vestuário, borracha e material plástico, impressão e gravações, transporte e derivados de petróleo. Dentre esses setores, apenas 
produtos de metal e vestuário estão entre aqueles com maior participação no VTI e na PO e, portanto, tiveram uma influência significativa sobre o índice geral da produtividade do estado. O setor de alimentos foi o que apresentou a maior taxa de variação da produtividade entre 2007 e 2016 para o Espírito Santo $(+4,3 \%)$ e para o Brasil $(+4,9 \%)$. Enquanto que a metalurgia apresentou a maior queda de produtividade na indústria do Brasil $(-4,1 \%)$ e ainda mais forte para o Espírito Santo (-20,5\%).

Na comparação dos setores da indústria com o desempenho no restante do Brasil, aqueles que apresentaram as maiores produtividades relativas em 2016 foram: celulose e papel, metalurgia e produtos de metal, minerais não-metálicos e máquinas e materiais elétricos. Assim, destaca-se que o setor de metalurgia do Espírito Santo, apesar da menor taxa de crescimento acumulado de produtividade entre 2007 e 2016, quando comparado ao Brasil, ainda é mais produtivo. Outro setor que apresentou desempenho positivo foi o de fabricação de produtos de metal que obteve o maior crescimento acumulado no estado $(+97,9 \%)$ e também aumentou sua produtividade relativa neste período, o que significa que a produtividade deste setor cresceu mais no estado do que no resto do país. Já o setor de derivados de petróleo do Espírito Santo, embora tenha alcançado uma taxa de crescimento acumulado elevada entre 2007 e 2016, ainda possui uma produtividade muito baixa se comparada ao resto do país.

Por fim, o estudo utilizou a decomposição da variação da produtividade para averiguar qual foi o efeito, se de composição ou de crescimento, que mais contribuiu para o desempenho das atividades industriais do Espírito Santo. Cabe destacar que nos setores de maior peso para a economia capixaba, o de alimentos foi o que obteve a maior variação positiva no período 2007-2016, resultado predominantemente explicado pela migração de trabalhadores entre setores. No setor de metalurgia, a retração da produtividade agregada teve impacto negativo maior pelo efeito crescimento. A soma dos efeitos em todos os setores da indústria de transformação capixaba resultou em um efeito crescimento de $1,87 \%$ e no efeito composição de $-14,52 \%$, mostrando que este último teve maior contribuição para retração da produtividade da indústria de transformação capixaba no período analisado. Assim, o efeito composição negativo aponta que as mudanças na estrutura produtiva, dada a produtividade relativa dos setores, não se deram com migração para os setores mais competitivos.

\section{Referências}

BONELLI, R. "Produtividade e armadilha do lento crescimento". In: de Negri, F. $R$ e Cavalcante, L. R. Produtividade no Brasil: Desempenho e Determinantes. Brasília: Ipea, 2014.

BONELLI, R. "Comparações Internacionais de Produtividade na Indústria e Tendências Setoriais: Brasil e EUA”. In: BARBOSA, N.; MARCONI, N.; CANÊDO PINHEIRO, M.; CARVALHO, L. (Orgs.). Indústria e Desenvolvimento Produtivo no Brasil. Rio de Janeiro: Editora Elsevier, p. 487-517, 2015.

BONELLI, R. e CANÊDO PINHEIRO, M. Produtividade na indústria de transformação: desempenho por atividade e tamanho de empresa, 2007-2013. In: Bonelli, R., Veloso, F., Pinheiro, A.C. (Orgs.). Anatomia da Produtividade no Brasil. Rio de Janeiro: Elsevier, p. 183-209, 2017. 
CANÊDO PINHEIRO, M.; BARBOSA FILHO, F. de H. Produtividade e convergência entre estados brasileiros: exercícios de decomposição setorial. Economia Aplicada, v. 15, n. 3, p. 417-442, 2011.

DE NEGRI, F.; CAVALCANTE, L. R. Produtividade no Brasil: desempenho e determinantes. Brasília: ABDI / IPEA, 2014.

DOSI, G., PAVITT, K., \& SOETE, L. The economics of technical change and international trade. LEM Book Series, 1990.

IEDI. A evolução da produtividade da indústria brasileira. Análise IEDI, 2018.

HIRSCHMAN, Albert O. The strategy of economic development. 1958.

KALDOR, N. Características do desenvolvimento econômico. Revista Brasileira de Economia. v.11, n.1, 1957.

KRUGMAN, Paul R. The age of diminished expectations: US economic policy in the 1990s. MIT press, 1997.

MAGAlHÃES, M. A.; RIBEIRO, A. P. L. Produtividade Industrial no Espírito Santo: uma análise para a primeira década do século XXI. Revista de Economia, v. 37, n. 1, 2011.

MENEZES FILHO, N.; CAMPOS, G.; KOMATSU, B. K. A Evolução da Produtividade no Brasil. Brasil. São Paulo, CPP Policy Paper n 12, ago. 2014.

PIRES, A. A indústria do petróleo e o caso do Espírito Santo. Análise dos grandes projetos de investimento no Espírito Santo. In: IJNS. Espírito Santo: Instituições, desenvolvimento e inclusão social. Vitória, 2010.

RODRIK, D. (2008). Industrial Policy for the Twenty-first Century. In: Rodrik, D. (ed.), One Economics, Many Recipes: Globalization, Institutions, and Economic Growth. Princeton University Press.

VELOSO, F.; MATOS, S.; COELHO, B. "Produtividade do Trabalho no Brasil: Uma Análise Setorial". In: BONELLI, R.; VELOSO, F. (Orgs.). Ensaios IBRE de Economia Brasileira II. Rio de Janeiro: Editora Elsevier, p. 75-107, 2014.

\section{Anexos}

Anexo 1. Evolução da produtividade do trabalho na indústria da transformação no Espírito Santo, 2008-

\begin{tabular}{lccccccccc}
\multicolumn{10}{c}{$2016,($ base: $2007=100)$} \\
\hline Atividades Industriais & 2008 & 2009 & 2010 & 2011 & 2012 & 2013 & 2014 & 2015 & 2016 \\
\hline Indústrias da transformação & 93,5 & 81,5 & 91,5 & 74,1 & 72,0 & 78,6 & 73,2 & 84,2 & 87,4 \\
Alimentos & 84,4 & 111,6 & 118,0 & 90,4 & 97,7 & 93,4 & 74,7 & 83,9 & 96,9 \\
Bebidas & 57,4 & 33,5 & 41,9 & 26,3 & 18,7 & 17,5 & 20,2 & 26,6 & 38,2 \\
Têxteis & 67,2 & 143,3 & 105,1 & 87,8 & 216,6 & 130,9 & 167,0 & 68,8 & 53,8 \\
Vestuário & 102,3 & 161,0 & 166,6 & 147,2 & 167,5 & 170,6 & 173,8 & 200,5 & 158,6 \\
Couro & 155,0 & 158,8 & 129,3 & 102,4 & 103,5 & 119,4 & 163,8 & 162,9 & 131,8 \\
Madeira & 98,2 & 76,0 & 104,1 & 66,1 & 84,8 & 117,9 & 97,6 & 90,5 & 132,7 \\
Celulose e papel & 89,9 & 120,1 & 125,5 & 107,6 & 109,2 & 122,5 & 86,1 & 158,8 & 123,6 \\
Impressão e gravações & 92,9 & 118,8 & 147,0 & 106,4 & 106,9 & 96,3 & 116,6 & 98,9 & 146,7 \\
Derivados de Petróleo & 47,0 & 44,6 & 131,3 & 108,4 & 94,4 & 208,3 & 126,5 & 135,8 & 135,6 \\
Químicos & 71,1 & 80,5 & 89,1 & 76,5 & 70,6 & 66,4 & 70,2 & 67,0 & 71,9
\end{tabular}




\begin{tabular}{lccccccccc} 
Borracha e plásticos & 109,5 & 128,6 & 182,6 & 153,0 & 174,2 & 234,7 & 213,7 & 176,8 & 153,4 \\
Minerais não-metálicos & 84,4 & 99,5 & 139,0 & 86,3 & 104,4 & 111,2 & 101,8 & 113,2 & 119,5 \\
Metalurgia & 101,2 & 52,5 & 52,6 & 50,0 & 29,4 & 39,5 & 41,1 & 39,4 & 48,3 \\
Produtos de metal & 93,2 & 153,4 & 219,2 & 121,2 & 154,1 & 158,8 & 178,1 & 221,7 & 197,9 \\
Máquinas e materiais elétricos & 127,2 & 270,0 & 223,9 & 110,1 & 86,1 & 75,4 & 77,3 & 101,7 & 118,4 \\
Máquinas e equipamentos & 99,2 & 98,5 & 120,8 & 99,5 & 249,0 & 196,6 & 84,8 & 87,0 & 58,9 \\
Veículos & 69,1 & 87,3 & 61,5 & 109,1 & 54,7 & 55,4 & 58,2 & 87,1 & 67,8 \\
Transporte & 80,7 & 81,7 & 118,2 & 141,7 & 320,6 & 122,5 & 230,3 & 95,4 & 138,8 \\
Móveis & 97,0 & 111,8 & 136,5 & 132,0 & 122,3 & 128,5 & 169,6 & 172,5 & 133,7 \\
Produtos diversos & 68,4 & 89,0 & 155,1 & 171,0 & 216,0 & 186,1 & 252,6 & 222,9 & 192,3 \\
Manutenção de máquinas & 97,4 & 92,0 & 100,1 & 103,4 & 118,0 & 114,1 & 107,7 & 108,0 & 96,2 \\
\hline
\end{tabular}

Fonte: PIA-Empresa/IBGE. Elaboração: Ideies/Sistema Findes.

Anexo 2. Produtividade relativa das atividades na indústria da transformação no Espírito Santo, $2007-$ 2016

\begin{tabular}{lcccccccccc}
\hline Atividades Industriais & 2007 & 2008 & 2009 & 2010 & 2011 & 2012 & 2013 & 2014 & 2015 & 2016 \\
\hline Indústria da Transformação & 0,97 & 0,97 & 0,95 & 0,97 & 0,88 & 0,89 & 0,95 & 0,93 & 1,04 & 0,99 \\
Alimentos & 0,96 & 0,86 & 1,16 & 1,09 & 0,93 & 1,00 & 0,91 & 0,77 & 0,83 & 0,85 \\
Bebidas & 1,05 & 0,69 & 0,38 & 0,47 & 0,34 & 0,25 & 0,24 & 0,28 & 0,34 & 0,48 \\
Têxteis & 0,56 & 0,41 & 0,89 & 0,58 & 0,55 & 1,38 & 0,83 & 1,15 & 0,44 & 0,33 \\
Vestuário & 0,38 & 0,49 & 0,70 & 0,65 & 0,56 & 0,66 & 0,67 & 0,75 & 0,88 & 0,62 \\
Couro & 0,69 & 1,08 & 1,17 & 0,86 & 0,75 & 0,71 & 0,79 & 1,05 & 1,05 & 0,79 \\
Madeira & 0,53 & 0,56 & 0,51 & 0,59 & 0,43 & 0,53 & 0,70 & 0,62 & 0,57 & 0,76 \\
Celulose e papel & 5,09 & 5,38 & 8,13 & 7,34 & 7,11 & 7,44 & 8,17 & 5,87 & 9,19 & 6,37 \\
Impressão e gravações & 0,36 & 0,39 & 0,52 & 0,57 & 0,46 & 0,49 & 0,45 & 0,55 & 0,51 & 0,66 \\
Derivados de Petróleo & 0,10 & 0,06 & 0,06 & 0,15 & 0,11 & 0,10 & 0,25 & 0,18 & 0,21 & 0,17 \\
Químicos & 0,79 & 0,61 & 0,83 & 0,85 & 0,81 & 0,78 & 0,71 & 0,79 & 0,68 & 0,65 \\
Borracha e plásticos & 0,42 & 0,51 & 0,61 & 0,80 & 0,75 & 0,88 & 1,13 & 1,05 & 0,87 & 0,70 \\
Minerais não-metálicos & 0,81 & 0,73 & 0,87 & 1,15 & 0,80 & 0,99 & 1,12 & 1,02 & 1,24 & 1,27 \\
Metalurgia & 1,96 & 2,08 & 1,69 & 1,46 & 1,78 & 1,10 & 1,33 & 1,38 & 1,26 & 1,50 \\
Produtos de metal & 0,56 & 0,55 & 0,94 & 1,28 & 0,83 & 1,12 & 1,08 & 1,30 & 1,68 & 1,36 \\
Máquinas e materiais elétricos & 0,79 & 1,04 & 2,37 & 1,79 & 1,07 & 0,86 & 0,71 & 0,78 & 0,96 & 1,04 \\
Máquinas e equipamentos & 0,62 & 0,65 & 0,75 & 0,78 & 0,73 & 1,87 & 1,51 & 0,67 & 0,69 & 0,46 \\
Veículos & 0,24 & 0,17 & 0,22 & 0,15 & 0,30 & 0,17 & 0,16 & 0,20 & 0,35 & 0,26 \\
Transporte & 0,28 & 0,26 & 0,30 & 0,41 & 0,57 & 1,47 & 0,53 & 1,03 & 0,40 & 0,49 \\
Móveis & 0,65 & 0,69 & 0,79 & 0,81 & 0,89 & 0,81 & 0,88 & 1,14 & 1,26 & 0,85 \\
Produtos diversos & 0,40 & 0,31 & 0,39 & 0,62 & 0,75 & 0,94 & 0,81 & 1,12 & 1,04 & 0,81 \\
Manutenção de máquinas & 0,79 & 0,84 & 0,81 & 0,88 & 0,97 & 1,08 & 1,02 & 0,95 & 0,92 & 0,76 \\
\hline & 0.618
\end{tabular}

Fonte: PIA-Empresa/IBGE. Elaboração: Ideies/Sistema Findes.

Anexo 3. Decomposição shift-share da produtividade, 2007-2016 - Espírito Santo

\begin{tabular}{lccc}
\hline Atividades Industriais & $\begin{array}{c}\text { Efeito } \\
\text { crescimento (\%) }\end{array}$ & $\begin{array}{c}\text { Efeito } \\
\text { composição (\%) }\end{array}$ & $\begin{array}{c}\text { Produtividade } \\
\text { total }\end{array}$ \\
\hline Indústria da Transformação & $-14,52$ & 1,87 & $-12,65$ \\
Alimentos & $-0,37$ & 4,72 & 4,35 \\
Bebidas & $-1,94$ & 0,51 & $-1,43$ \\
Têxteis & 0,00 & 0,00 & 0,00 \\
Vestuário & $-0,17$ & $-0,25$ & $-0,42$ \\
Couro & 0,74 & $-0,61$ & 0,13 \\
Madeira & 0,10 & $-0,03$ & 0,07 \\
\hline
\end{tabular}




\begin{tabular}{lcccc}
\cline { 1 - 1 } Celulose e papel & 0,25 & $-0,28$ & $-0,03$ \\
Impressão e gravações & 3,42 & $-4,98$ & $-1,56$ \\
Derivados de Petróleo & 0,15 & 0,16 & 0,31 \\
Químicos & 0,22 & $-0,32$ & $-0,09$ \\
Borracha e plásticos & $-0,90$ & 0,82 & $-0,09$ \\
Minerais não-metálicos & 0,00 & 0,00 & 0,00 \\
Metalurgia & 0,45 & $-0,14$ & 0,31 \\
Produtos de metal & 2,31 & 0,26 & 2,57 \\
Máquinas e materiais elétricos & $-21,42$ & 0,89 & $-20,52$ \\
Máquinas e equipamentos & 2,51 & 0,61 & 3,12 \\
Veículos & 0,00 & 0,00 & 0,00 \\
Transporte & 0,33 & 1,83 & 2,16 \\
Móveis & $-0,68$ & $-1,40$ & $-2,08$ \\
Produtos diversos & $-0,14$ & $-0,13$ & $-0,27$ \\
Manutenção de máquinas & 0,18 & 0,62 & 0,80 \\
\hline
\end{tabular}

Fonte: PIA-Empresa/IBGE. Elaboração: Ideies/Sistema Findes.

Anexo 4. Decomposição shift-share da produtividade, 2007-2016 - Brasil

\begin{tabular}{lccc}
\hline Atividades Industriais & $\begin{array}{c}\text { Efeito } \\
\text { crescimento }(\%)\end{array}$ & $\begin{array}{c}\text { Efeito composição } \\
(\%)\end{array}$ & $\begin{array}{c}\text { Produtividade } \\
\text { total }\end{array}$ \\
\hline Indústria da Transformação & $-14,06$ & $-0,27$ & $-14,33$ \\
Alimentos & 1,41 & 3,51 & 4,92 \\
Bebidas & $-0,66$ & 0,62 & $-0,04$ \\
Têxteis & $-0,27$ & $-0,02$ & $-0,29$ \\
Vestuário & $-0,12$ & $-0,42$ & $-0,54$ \\
Couro & $-0,03$ & 0,00 & $-0,03$ \\
Madeira & 0,23 & $-0,33$ & $-0,10$ \\
Celulose e papel & $-0,08$ & $-0,37$ & $-0,45$ \\
Impressão e gravações & $-0,04$ & $-0,16$ & $-0,20$ \\
Derivados de Petróleo & $-0,20$ & $-0,06$ & $-0,26$ \\
Químicos & $-2,20$ & $-1,03$ & $-3,23$ \\
Borracha e plásticos & $-1,12$ & 0,96 & $-0,16$ \\
Minerais não-metálicos & $-0,82$ & 0,30 & $-0,51$ \\
Metalurgia & $-0,29$ & $-0,07$ & $-0,36$ \\
Produtos de metal & $-0,80$ & 0,34 & $-0,45$ \\
Máquinas e materiais elétricos & $-3,00$ & $-1,11$ & $-4,10$ \\
Máquinas e equipamentos & $-0,72$ & $-0,44$ & $-1,16$ \\
Veículos & $-0,17$ & $-0,72$ & $-0,89$ \\
Transporte & $-0,28$ & $-0,07$ & $-0,35$ \\
Móveis & $-0,99$ & $-0,47$ & $-1,46$ \\
Produtos diversos & $-3,52$ & $-1,21$ & $-4,72$ \\
Manutenção de máquinas & $-0,41$ & 0,00 & $-0,40$ \\
\hline
\end{tabular}

Fonte: PIA-Empresa/IBGE. Elaboração: Ideies/Sistema Findes. 